This document is confidential and is proprietary to the American Chemical Society and its authors. Do not copy or disclose without written permission. If you have received this item in error, notify the sender and delete all copies.

\title{
Development and application of the diffusive gradients in thin-films technique for measuring psychiatric pharmaceuticals in natural waters
}

\begin{tabular}{|r|l|}
\hline Journal: & Environmental Science \& Technology \\
\hline Manuscript ID & es-2019-031669.R1 \\
\hline Manuscript Type: & Article \\
\hline Date Submitted by the & 29-Aug-2019 \\
\hline Complete List of Authors: & $\begin{array}{l}\text { Fang, Zhou; Nanjing University } \\
\text { Li, Kexin; Nanjing University, School of the Environment } \\
\text { Li, Yuan; Nanjing University } \\
\text { Zhang, Hao; Lancaster University, Lancaster Environment Centre } \\
\text { Jones, Kevin; Lancaster University, Lancaster Environment Centre } \\
\text { Liu, Xinyu; Scientific Institute of Pearl River Water Resources Protection } \\
\text { Liu, Shengyu; Scientific Institue of Pearl River Water Resources } \\
\text { Protection, Monitoring Centre of Pearl River Valley Aquatic Environment } \\
\text { Ma, Lena; University of Florida, } \\
\text { Luo, Jun; Nanjing University, School of the Environment }\end{array}$ \\
\hline
\end{tabular}

\section{SCHOLARONE Manuscripts}


1 Development and application of the diffusive gradients in thin-films

2 technique for measuring psychiatric pharmaceuticals in natural

\section{3 waters}

4 Zhou Fang ${ }^{1}$, Kexin $\mathrm{Li}^{1}$, Yuan $\mathrm{Li}^{1}$, Hao Zhang ${ }^{2}$, Kevin C. Jones ${ }^{1,2}$, Xinyu Liu ${ }^{3}$,

$5 \quad$ Shengyu $\mathrm{Liu}^{3}$, Lena Q. $\mathrm{Ma}^{1,4}$, Jun $\mathrm{Luo}^{1 *}$

$6{ }^{1}$ State Key Laboratory of Pollution Control and Resource Reuse, School of the

7 Environment, Nanjing University, Nanjing, Jiangsu 210023, P. R. China

$8{ }^{2}$ Lancaster Environment Centre, Lancaster University, Lancaster LA1 4YQ, United

$9 \quad$ Kingdom

$10{ }^{3}$ Monitoring Centre of Pearl River Valley Aquatic Environment, Scientific Institute

11 of Pearl River Water Resources Protection, Guangzhou 510611, China

$12{ }^{4}$ Soil and Water Science Department, University of Florida, Gainesville, Florida

13 32611, United States

14 * Corresponding author, 0086-25-89680632, esluojun@nju.edu.cn 


\section{ABSTRACT}

Psychiatric pharmaceuticals are widely distributed in the aquatic environment and have attracted recent attention due to their potential for environmental effects. A robust and reliable in situ passive sampling approach, the diffusive gradients in thin-films (DGT) technique, is developed here to measure 14 psychiatric pharmaceuticals. A new binding material, mixed-mode cation exchange resin (Poly-Sery MCX, 40 $\mu \mathrm{m}, \mathrm{CNW}$, Germany), was used for the first time in DGT and compared to XAD and HLB. Reliable elution efficiencies of the pharmaceuticals from the binding gels were obtained in methanol/ammonia and diffusion coefficients for all the compounds were determined. The influence of diffusive layer thickness (0.515-2.015 mm), deployment time $(3-168 \mathrm{~h})$, and important environmental conditions $-\mathrm{pH}(3.02-9.45)$, ionic strength (0.0001-0.5 M) and dissolved organic matter $\left(0-20 \mathrm{mg} \mathrm{L}^{-1}\right)$ - were evaluated. The capacity of XAD, HLB and MCX gels for binding all the test pharmaceuticals was $\sim 335 \mu \mathrm{g}$ per disc, meaning that DGT could theoretically be deployed for over 30 months, if there are no competitive effects or confounding factors. The uptake kinetics of psychiatric pharmaceuticals onto MCX gel were much faster than to XAD and HLB gels in the first hour. DGT measured concentrations of test pharmaceuticals at two sample points in a river (over 6 days) were comparable to those obtained by grab sampling. This study demonstrates the accuracy and reliability of DGT for measuring psychiatric pharmaceuticals across the wide range of freshwater conditions found in the natural environment. 


\section{INTRODUCTION}

Psychiatric pharmaceuticals are now widely used in many modern societies to treat mental health conditions. ${ }^{1}$ For example, in the United Kingdom, the prescription of fluoxetine (FHY) increased 19\% between 2011-2016. ${ }^{2}$ The number of people using antidepressants in Denmark increased from 250k to 380k from 2000 to 2014, ${ }^{3}$ while in the United States, the total quantities of benzodiazepines used to treat insomnia trebled from 1.1 to 3.6 kilogram per 100,000 adults between 1996 and 2013. ${ }^{4}$ Despite passing through wastewater treatment processes, psychiatric pharmaceuticals have become ubiquitous in receiving waters.5-8 For example, diazepam concentrations in many European river waters have been reported in the several 10s ng L ${ }^{-1}$ range. ${ }^{6,8,9}$ Average FHY concentrations in effluents from China mental hospitals were $\sim 21 \mathrm{ng} \mathrm{L}{ }^{-1}$ in a Chinese study, ${ }^{10}$ and $\sim 55 \mathrm{ng} \mathrm{L}^{-1}$ in influents and effluents in Italy. ${ }^{11}$ Oxazepam concentrations were as high as $942 \mathrm{ng} \mathrm{L}^{-1}$ in sewage influents of some psychiatric hospitals in China. ${ }^{12}$ Studies have reported negative effects of psychiatric pharmaceuticals on aquatic animals ${ }^{13,14}$ and human health, ${ }^{15}$ by directly acting on the central nervous system and disrupting neuro-endocrine signaling. ${ }^{7}$

Precise measurement and monitoring are pre-requisites to better understand the fate and biogeochemical behavior of these compounds and to further assess their potential effect on ecosystems and human health. So far studies have mainly simply been conducted by spot grab sampling. Although grab sampling is the most commonly used method for organic contaminants monitoring in waters, it usually needs large 
volume water samples for solid phase extraction (SPE), with potential problems of sample storage, shipment, pretreatment and labour costs, while grab sampling only provides a snapshot of target analyte concentrations at the given sampling time, rather than giving more meaningful time weighted average concentrations (TWA). ${ }^{16}$

As a power-free sampling method, passive sampling techniques are now increasingly being used to pre-concentrate the analytes of interest onto binding agents in situ. ${ }^{17}$ Passive sampling techniques are considered by many to be more convenient, economical, and time-saving and to give more meaningful TWA results on the biologically available fraction of contaminants in waters. The most frequently used passive sampling devices for organic contaminants in waters have been semi-permeable membrane devices (SPMDs) ${ }^{18,} 19$ and polar organic chemical integrative sampler (POCIS). ${ }^{17}$ However, their measurements are influenced by the hydrodynamic (flow) conditions of the water, due to the influence of the diffusion boundary layer (DBL) on sampling rate. They require calibration to correct for the effect of the DBL. In contrast, the diffusive gradients in thin films (DGT) technique contains a well-defined diffusive layer which controls the uptake of analytes and reduces the effect of the DBL on the measurement. ${ }^{20}$ DGT provides in situ sampling of trace chemicals in water without field calibration. ${ }^{21}$ The principle of DGT is based on Fick's first law of diffusion. The concentration of analyte measured by DGT, $C_{\mathrm{DGT}}$, is expressed as eq 1 .

$C_{\mathrm{DGT}}=\frac{\mathrm{M} \Delta \mathrm{g}}{\mathrm{DA} t}$

$M$ is the measured mass of target analyte accumulated in the binding layer, $\Delta g$ 
81 expresses the thickness of the diffusive layer, $D$ is the diffusion coefficient of the target analyte in the diffusive layer, $t$ is the exposure time, and $A$ is the window area of the DGT device.

Invented in the 1990s for work on heavy metals and nutrients, DGT has been developed over recent years for many classes of trace organic contaminants, including antibiotics, ${ }^{22}$ pesticides,${ }^{23}$ herbicides,${ }^{24}$ bisphenols (BPs), ${ }^{25}$ perfluoroalkyl substances (PFASs), ${ }^{26}$ organophosphorus flame retardants (OPFRs), ${ }^{16}$ and pharmaceuticals and personal care products (PPCPs). ${ }^{27}$ Most studies have used HLB and XAD18 as the binding material for DGT devices.

The aim of this study is to develop a new DGT method for measuring psychiatric pharmaceuticals in waters and apply it to natural aquatic systems. Anew binding gel was prepared using a strong cation exchange resin, MCX, because psychiatric pharmaceuticals are mostly in the cationic form in natural waters. ${ }^{10}$ The two commonly used resins, XAD18 and HLB, were also used in test experiments to find the most suitable binding gels for 14 of the most commonly used psychiatric pharmaceuticals.

7 Diffusion coefficients required to calculate environmental concentrations of the psychiatric pharmaceuticals from a DGT deployment were determined and reported for the first time. To ensure DGT can be used to sample these compounds across the full range of natural environments, the effects of environmental conditions ( $\mathrm{pH}$, ionic strength, and dissolved organic matter), diffusive gel thickness, deployment time, storage time and competition between different psychiatric pharmaceuticals on DGT 
103

104

performances were systemically tested. Finally, the three different types of DGT devices with different binding gels were deployed in the field and compared with grab sampling, to check its reliability and robustness for measurement and monitoring of psychiatric pharmaceuticals.

\section{EXPERIMENTAL SECTION}

Chemicals and Reagents. Antidepressants and hypnagogues are two large classes of commonly used psychiatric pharmaceuticals. The following antidepressants were selected for study from 4 types of the most commonly used classes, namely: tricyclic antidepressants (TCAs); selective serotonin reuptake inhibitor (SSRIs); noradrenalin-dopamine re-uptake inhibitor (NDRI) and norepinephrine and specific 5-hydroxytryptamine antidepressant (NaSSA). ${ }^{28,29}$ Target compounds were: fluoxetine hydrochloride (FHY), risperidone (RIS), caffeine (CAF), clomipramine (CLO), fluvoxamine maleate (FMA), mirtazapine (MIR), perphenazine (PER), amitriptyline (AMI), and bupropion hydrochloride (BUP). Benzodiazepines are more common hypnagogues in clinical application than barbiturates, ${ }^{30}$ so the following target analytes were selected: estazolam (EST), diazepam (DIA), temazepam (TEM), alprazolam (ALP), and oxazepam (OXA). All psychiatric pharmaceutical standards were purchased from Merck (Germany). ${ }^{13} \mathrm{C}_{3}$-caffeine was used as an internal standard and purchased from Cambridge Isotope Laboratories (CIL, USA). Physicochemical properties of all target psychiatric pharmaceuticals are described in the Supporting Information (Table S1). HPLC grade methanol and ammonia water were purchased from Merck (Germany) and CMW (Germany), respectively. 
DGT Preparation. A standard piston DGT device consists of a 0.5 -mm-thick agarose-based binding gel, a 0.75-mm-thick agarose-based diffusive gel, and a filter membrane, which are sandwiched by an ABS-based plastic molding (DGT Research Ltd., UK). Preparation of the agarose diffusive gel has been described previously. ${ }^{16}$ Adsorption of target psychiatric pharmaceuticals on DGT-related materials, such as agarose diffusive gels, filter membranes, and DGT plastic molding, was tested. Agarose diffusive gel discs and four types of filter membranes (all with $2.5 \mathrm{~cm}$ diameter) [GH polypro (GHP, $0.114 \mathrm{~mm}$ thick, Pall, USA), Nuclepore track-etched polycarbonate membrane (PC, $0.015 \mathrm{~mm}$ thick, Whatman, USA), polyethersulfone (PES, $0.14 \mathrm{~mm}$ thick, Pall, USA), and polytetrafluoroethylene (PTFE, $0.14 \mathrm{~mm}$ thick, Pall, USA)], were separately immersed in $10 \mathrm{~mL}$ mixed solution of the 14 target chemicals, each at a concentration of $20 \mu \mathrm{g} \mathrm{L} \mathrm{L}^{-1}$, while a set of DGT plastic moldings was immersed in $200 \mathrm{~mL}$ solution of the same composition. All solutions were shaken horizontally for $24 \mathrm{~h}$. The adsorbed mass of the target chemicals was calculated by the difference of solution concentrations before and after the adsorption experiment.

The binding gels were prepared using three types of resins, Amberlite ${ }^{\mathrm{TM}}$ macroporous adsorbents resin XAD18 (XAD18, $75 \mu \mathrm{m}$ particle size, Rohm and Hass Co., USA), hydrophilic lipophilic balanced resin (HLB, collected from Oasis-HLB SPE cartridges, $60 \mu \mathrm{m}$ particle size, Waters, UK), and Poly-Sery MCX (40 $\mu \mathrm{m}$ particle size, MCX, CNW, Germany), and tested for their performance. Before gel making, these resins were activated with methyl alcohol for $0.5 \mathrm{~h}$ and then thoroughly washed using Milli-Q (18.2 M $\Omega \mathrm{cm}$, Millipore, USA) water. The procedure for 
making the binding gels was: $2 \mathrm{~g}$ (wet weight after pre-treatment) of resins was added into $10 \mathrm{~mL}$ of $2 \%$ agarose solution and then heated to boiling together. This agarose solution was pipetted between two preheated glass plates $\left(\sim 70{ }^{\circ} \mathrm{C}\right)$ separated by 0.5 mm thick PTFE spacer and left to cool down to room temperature. Once the gel was set, open the glass plates with care and then cut into discs with a diameter of $2.5 \mathrm{~cm}$.

Uptake Kinetics and Elution Efficiencies of Binding Gels. XAD18, HLB or MCX based binding gel discs were immersed separately in $40 \mathrm{~mL}$ of $100 \mu \mathrm{g} \mathrm{L}^{-1}$ psychiatric pharmaceutical solutions containing $0.01 \mathrm{M} \mathrm{NaCl}$, and shaken horizontally for up to $24 \mathrm{~h}$. At different times from $0.5 \mathrm{~min}$ to $24 \mathrm{~h}, 50 \mu \mathrm{L}$ samples were taken from the solutions for analysis. The masses of target psychiatric pharmaceuticals bound by the gel discs at different time were calculated by the difference between the initial concentration and the concentration at collection of solution subsamples at different time intervals. A control solution having the same compositions without gel immersion was set to test the potential adsorption of target chemicals onto the container wall.

Eq. S1 indicates that a stable elution efficiency is important to calculate the adsorbed masses of analytes and hence assess the DGT-measured concentrations. Therefore, to determine elution efficiencies of target psychiatric pharmaceuticals, XAD (containing XAD18 resin), HLB (containing HLB resin), and MCX (containing MCX resin) binding gel discs were immersed separately in $10 \mathrm{~mL}$ of pharmaceuticals

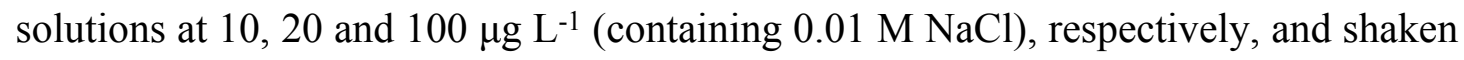
for $24 \mathrm{~h}$ at $25{ }^{\circ} \mathrm{C}$. Psychiatric pharmaceuticals adsorbed by the binding gel discs were 
169

170

171

172

173

eluted using $10 \mathrm{~mL}$ of methanol containing $0.1 \%, 5 \%$, or $10 \%$ (volume ratio) ammonia solution (the initial concentration of ammonia solution is $13 \mathrm{~mol} \mathrm{~L}^{-1}$ ), respectively, in an ultrasonic bath for 3 hours. After filtration using $0.22 \mu \mathrm{m}$ pore size PTFE filter membranes, the elution solutions were analyzed using UPLC-MS/MS (Qsight 210, PerkinElmer, USA) (see SI for details). Elution efficiency is calculated as the proportion of measured masses of target psychiatric pharmaceuticals in eluents to their masses adsorbed by the binding gel discs, calculated by the concentration difference of the solution between before and after uptake experiments.

Measurement of Diffusion Coefficients. A diffusion cell device ${ }^{16}$ consisting of two stainless steel compartments was used to measure diffusion coefficients, $D_{\text {cell }}$, of the 14 psychiatric pharmaceuticals. A $0.75 \mathrm{~mm}$ thick agarose diffusive gel was held in circular windows (diameter $1.5 \mathrm{~cm}$ ) between the two compartments. $50 \mathrm{~mL}$ of $0.01 \mathrm{M}$ $\mathrm{NaCl}$ solution containing $1.0 \mathrm{mg} \mathrm{L}^{-1}$ psychiatric pharmaceuticals was added to the source compartment, while $50 \mathrm{~mL}$ of $0.01 \mathrm{M} \mathrm{NaCl}$ solution without pharmaceuticals was added to the receptor compartment. The solution in the two compartments had the same $\mathrm{pH}(5.63 \pm 0.49)$ and temperatures $\left(25.0 \pm 0.5^{\circ} \mathrm{C}\right)$. The solutions were well stirred during a $4 \mathrm{~h}$ experiment. Solution samples of $0.2 \mathrm{~mL}$ were pipetted from both compartments at 30-min intervals for instrumental analysis. $D_{\text {cell }}$ was calculated using eq 2:

$$
D_{\text {cell }}=\operatorname{slope} \frac{\Delta g}{C A}
$$

$\Delta g$ is the thickness of the agarose diffusive gel, $C$ represents concentrations of the psychiatric pharmaceuticals in the source compartment, and $A$ is the area of the 
191

192

193

194

195

196

197

198

199

200

201

202

203

204

205

206

207

208

209

210

211

212

window between the two compartments. The slope was evaluated by plotting the diffused masses of the psychiatric pharmaceuticals versus diffusion time.

Diffusion coefficients obtained from DGT measurement, $D_{\mathrm{DGT}}$, were also measured to validate the measurement of $D_{\text {cell }}$. Eight DGT devices were deployed in $2.5 \mathrm{~L}$ well-stirred solutions containing the 14 psychiatric pharmaceuticals at $20 \mu \mathrm{g} \mathrm{L}^{-1}$ and $0.01 \mathrm{M} \mathrm{NaCl}$ for $24 \mathrm{~h}$. The concentrations measured by DGT were assumed to equal the solution concentrations, according to the theory of the DGT technique. $D_{\text {DGT }}$ was calculated using eq 1.

$D$ values, $D_{\mathrm{T}}$, at different temperatures $\left(\mathrm{T},{ }^{\circ} \mathrm{C}\right)$ can be calculated from the value at $25{ }^{\circ} \mathrm{C}\left(D_{25}\right)$, using eq $3^{31}$ as follows:

$$
\log D_{\mathrm{T}}=\frac{1.37023(\mathrm{~T}-25)+8.36 \times 10^{-4}(\mathrm{~T}-25)^{2}}{109+\mathrm{T}}+\log \frac{D_{25}(273+\mathrm{T})}{298}
$$

DGT Performance Tests under Different Conditions. Effects of $p H$, IS, and DOM. DGT devices equipped with $0.5 \mathrm{~mm}$ thick binding gel (XAD, HLB, or MCX), $0.75 \mathrm{~mm}$ thick agarose diffusive gel, and $0.015 \mathrm{~mm}$ PC filter membrane were used in these validation experiments. To test the effect of $\mathrm{pH}$, IS and DOM on DGT performance, DGT devices were deployed in $2.5 \mathrm{~L}$ well-stirred solutions containing psychiatric pharmaceuticals at $20 \mu \mathrm{g} \mathrm{\textrm {L } ^ { - 1 }}$ for $24 \mathrm{~h}$ and $6 \mathrm{~d}$ with: (a) various $\mathrm{pH}$ values (changing from 3.02 to $9.45,0.01 \mathrm{M} \mathrm{NaCl}$, and $0 \mathrm{mg} \mathrm{L}^{-1}$ humic acid; $\mathrm{pH}$ was adjusted using $\mathrm{HCl}$ and $\mathrm{NaOH}$. DGT devices were deployed when the $\mathrm{pH}$ of water was completely stable (after 3-4 days), and during the experiment the $\mathrm{pH}$ was tested every $6 \mathrm{~h}$ to ensure its stability; (b) various $\mathrm{NaCl}$ concentrations (from $0.0001 \mathrm{M}$ to $0.5 \mathrm{M}$, $\mathrm{pH}=5.72 \pm 0.2$, and $0 \mathrm{mg} \mathrm{L}^{-1}$ humic acid); and (c) various concentrations of humic 
213 acid (Aladdin, fulvic acid $\geq 90 \%$ ) (from 0 to $20 \mathrm{mg} \mathrm{L}^{-1}, 0.01 \mathrm{M} \mathrm{NaCl}$, and $\mathrm{pH}=5.50$ $214 \pm 0.2)$

215 Diffusion Layer Thickness and Deployment Time Dependence. To demonstrate the 216 dependence of mass uptake by DGT devices on the thickness of the diffusion layer, 217 the DGT devices equipped with agarose diffusive gels of different thicknesses $218(0.5-2.0 \mathrm{~mm})$ were deployed in $2.5 \mathrm{~L}$ well-stirred solutions containing psychiatric 219 pharmaceuticals at $20 \mu \mathrm{g} \mathrm{L}^{-1}$ and $0.01 \mathrm{M} \mathrm{NaCl}$ at $25 \pm 0.5^{\circ} \mathrm{C}$ for $24 \mathrm{~h}$. To investigate 220 the dependence on deployment time, the DGT devices were deployed in 7 L 221 well-stirred solutions containing psychiatric pharmaceuticals at $3 \mu \mathrm{g} \mathrm{L}^{-1}$ and $0.01 \mathrm{M}$ 222 $\mathrm{NaCl}$ at $25 \pm 0.5^{\circ} \mathrm{C}$ and retrieved at different times (from 3 to $168 \mathrm{~h}$ ). Ratios, $R$ values, of concentrations measured by DGT, $\mathrm{C}_{\mathrm{DGT}}$, to concentrations in 224 water, $\mathrm{C}_{\text {soln }}$, should be in the range of $0.9-1.1$. XAD binding gels, HLB-DGT containing HLB binding gels, and MCX-DGT 227 containing MCX binding gels) were deployed in the Xijiang river, to test the 228 applicability and the robustness of the DGT technique for measuring the 14 psychiatric pharmaceuticals in situ from a real aquatic system. The Xijiang river, with 230 a length of $2214 \mathrm{~km}$, is the main stream of the Pearl River system, China. Two 231 sampling sites were selected, in Zhaoqing (112 $\left.43^{\prime} 12^{\prime \prime} \mathrm{E}, 23^{\circ} 10^{\prime} 12^{\prime \prime} \mathrm{N}\right)$ and Zhuhai $232\left(113^{\circ} 18^{\prime} 59^{\prime \prime} \mathrm{E}, 22^{\circ} 8^{\prime} 50^{\prime \prime} \mathrm{N}\right)$, in the middle reach and the downstream section of Xijiang 233 river, respectively. Standard DGT devices were fixed on a Plexiglass deployment 234 system with the exposure windows outward to ensure that each DGT device had equal 
contact with the water (Figure S9). The Plexiglass deployment systems were placed about $1 \mathrm{~m}$ below the water surface for 6 days, together with a temperature data logger (iButton DS1921G, Maxim, USA) set to record temperature every 2 h. Each type of DGT device was in triplicate at the same site for the same sampling time. The grab water samples were collected using a Plexiglas water sampler every 2 days during the 6-d DGT deployment (day 0, 2, 4 and 6). The water samples were kept in glass bottles and brought back to the laboratory immediately. Standard deviations were evaluated from the 4 grab samples. DGT field deployments were implemented in August, September and October 2018. There were heavy rains every day from the third day of the August field deployments, and heavy rains every day during the September field deployment. Internal standard of $10 \mathrm{ng}{ }^{13} \mathrm{C}_{3}$-caffeine was spiked in water samples (1 L), and then concentrated with HLB cartridges (Waters, 6 cc $150 \mathrm{mg}$ ), which were eluted three times using $3 \mathrm{~mL}$ of methanol with $5 \%$ ammonia. The eluents were combined and evaporated by blowing down to dryness under nitrogen, then re-dissolving with $1 \mathrm{~mL}$ methanol. The final solution was filtered using PTFE filter membranes with $0.22 \mu \mathrm{m}$ pore size ready for instrumental analysis.

\section{RESULTS AND DISCUSSION}

\section{Uptake kinetics and elution efficiencies of the psychiatric pharmaceuticals}

onto binding gels. Fast uptake of target analytes by the binding gels is the prerequisite for assuring the interface concentration between the binding gel and the diffusive gel is effectively zero, so that equation 1 can be used to obtain DGT measured concentrations accurately. ${ }^{16}$ Figures 1 and S2 show that the mass of test 
257 pharmaceutical accumulated onto each type of binding gel disc increased rapidly with 258 time in the first $2 \mathrm{~h}$. The adsorbed masses after $3 \mathrm{~h}$ were similar to those after $24 \mathrm{~h}$. 259 Uptake rates onto MCX gel discs were faster than those onto XAD and HLB gel discs 260 in the first hour. For example, XAD and HLB gel discs only adsorbed $17 \%$ and 39\% 261 of the CAF in the original solutions, respectively, while MCX accumulated $47 \%$ in 262 the first hour. MCX is a strong cation exchange resin, more suitable for psychiatric pharmaceuticals, which mainly exist as cations in freshwaters. According to Fick's law of diffusion, the minimum uptake amount by the binding gel at the first 5 minutes must not be less than the theoretical diffusion amount through the diffusive gels, to make sure that the uptake of target analytes on binding gel is rapid enough to keep the concentration effectively zero at the binding/diffusive gel interface. ${ }^{27}$ In our results, for example, the measured mass of OXA accumulated on XAD, HLB and MCX gel after $5 \mathrm{~min}$ (Figure 1) corresponds to a flux of $0.30,0.22$ and $1.15 \mathrm{ng} \mathrm{cm}^{-2} \mathrm{~s}^{-1}$. The flux through a diffusion layer of a DGT with a $0.765 \mathrm{~mm}$ diffusive gel and filter 271 membrane is only $0.07 \mathrm{ng} \mathrm{cm}^{-2} \mathrm{~s}^{-1}$, when the OXA concentration is $1 \mathrm{mg} \mathrm{L}^{-1}$, which is 272 exceptionally high for natural water bodies including wastewater treatment plants. 273 This indicates the three binding gels all meet the requirement of the DGT technique 274 regarding uptake rates, but MCX had the highest uptake rate for the first few minutes. 275 CAF had similar results, however, XAD may fail to meet the requirement of CAF in 276 long-term deployment, due to its relatively low binding capacity.

277 A stable elution efficiency for a given analyte can precisely evaluate masses taken 278 up by the binding gels and then assure the correct calculation of DGT measured 
concentrations. Eluents from the XAD, HLB and MCX binding gels contained different percentages of ammonia water, because ammonia can help to release the bound psychiatric pharmaceuticals (data not shown). Although elution efficiencies of XAD and HLB binding gels for most of the studied pharmaceuticals were a little higher than MCX binding gels, all 3 binding gels generally had stable elution efficiencies (Table S3) for different amounts loaded on the binding gels. The elution efficiencies of XAD gels for psychiatric pharmaceuticals ranged from 83 to $97 \%$, similar to values obtained for antibiotics ${ }^{22}$ and illicit drugs ${ }^{32}$. Most of the elution efficiencies from HLB binding gels in this study were $>80 \%$, but a little lower than those for anionic pesticides ${ }^{23}$ and some polar pesticides and antibiotics. ${ }^{33}$ Although MCX had lower elution efficiencies for a few tested pharmaceuticals (FHY, 63\%; FMA, 55\%; and OXA, $63 \%$ ), for most compounds the elution efficiencies were in the range $82-100 \%$. The relatively lower elution efficiencies showed the strong binding ability of MCX binding gels to the tested pharmaceuticals.

Diffusion Coefficient Measurements. Accurate measurement of the diffusion coefficients of target analytes in the diffusion gel is required for calculation of DGT measured concentrations. Masses of the tested psychiatric pharmaceuticals that diffused through the diffusive gel from the source compartment to the receptor compartment of a diffusion cell were linearly correlated $\left(r^{2}=0.997-0.999\right.$, at $\left.25^{\circ} \mathrm{C}\right)$ with time (Figure S3). Values of $D_{\text {cell, }}$ evaluated according to eq 2, are given in Table S4. $D_{\mathrm{DGT}} / D_{\text {cell }}$ ratios were in the range $0.93-1.13$, confirming the reliability of diffusion coefficients measured by both approaches. 

(IQLs) of UPLC-MS/MS, DGT blank concentrations, and DGT method quantitation limits (MQLs) are listed in Table 1. DGT blank concentrations of the tested psychiatric pharmaceuticals were evaluated by determining the mass of the analytes in XAD, HLB, and MCX binding gels retrieved from DGT device s left in a clean bag without deployment. Concentrations caused by electronic noise of instruments of the tested compounds in the XAD, HLB, and MCX blank gels were low $(0-0.13 \mathrm{ng}$ per disc). Only PER had higher masses in the blank gels $(0.41,0.53$ and 0.83 ng per disc 309 for XAD, HLB, and MCX gels, respectively). The IQL was the lowest point of the calibration curve which can be quantitatively evaluated within $\pm 20 \%$ of its nominal 311 value. ${ }^{16}$ MQLs were evaluated from the IQLs, assuming that DGT devices were 312 deployed for 6 days at $25{ }^{\circ} \mathrm{C}$. Similar ranges of MQLs $\left(0.07--0.97 \mathrm{ng} \mathrm{L}^{-1}\right)$ were obtained for XAD-, HLB-, and MCX-DGT. According to the literature, WWTPs have 314 high concentrations of psychiatric pharmaceuticals. For example, AMI concentrations 315 in some WWTP influents and effluents of Canada were 46-283 and 26-128 ng L-1 in 316 $2012^{15}$ and FHY in some WWTP effluents of USA was at 40-73 ng L $\mathrm{L}^{-1} 34$ and $20 \mathrm{ng}$ $\mathrm{L}^{-1}$ in some WWTP influents of China. ${ }^{35}$ Concentrations of BUP in some WWTP 318 influents was $70-191 \mathrm{ng} \mathrm{L}^{-1}$ (for Canada) ${ }^{22}$ and those of DIA were $33 \mathrm{ng} \mathrm{L}^{-1}$ (for 319 Germany) $)^{6}$. In surface water, their concentrations were lower than WWTPs, but 320 often $>1 \mathrm{ng} \mathrm{L}^{-1}$, i.e. FHY was at $12^{34}$ and $1.4 \mathrm{ng} \mathrm{L^{-1 }}{ }^{36}$ for USA and China and OXA 321 and DIA in Germany was $40^{37}$ and $53 \mathrm{ng} \mathrm{L}^{-1},{ }^{38}$ respectively. These comparisons 322 indicate that DGT, coupled with UPLC-MS/MS, can meet the required sensitivity for 
323

measurement of psychiatric pharmaceuticals in WWTPs and surface waters. Furthermore, the deployment time can be extended, or more DGT devices deployed and combined into one sample, to improve sensitivity in waters with extremely low concentrations.

Effects of pH, Ionic Strength and DOM on DGT performance. pH, ionic strength (IS), and dissolved organic matters (DOM) are the main aquatic parameters which can influence DGT performance. As shown in Figures 2 and S5a, when solution $\mathrm{pH}$ varied from 3 to $\sim 9.5$, the ratio, $R$ value, of $\mathrm{C}_{\mathrm{DGT}} / \mathrm{C}_{\text {soln }}$ basically fell into the acceptable value range of $0.9-1.1$ during both $24 \mathrm{~h}$ and $6 \mathrm{~d}$ deployments, with no significant difference between the three types of DGT devices tested (ANOVA, $p>$ 0.05). This shows that $\mathrm{pH}$ across the range found in natural waters does not affect sampler performance, so that the DGT can be used to monitor waters of different properties, and in experimental studies where $\mathrm{pH} / \mathrm{IS} / \mathrm{DOM}$ are studied as variables. It is well documented that XAD-DGT can measure illicit drugs ${ }^{32}$ and XAD-DGT and HLB-DGT can measure endocrine disrupting chemicals (EDCs) ${ }^{39}$ in waters across a similar $\mathrm{pH}$ range tested in this study. However, Chen et al. ${ }^{27}$ reported $\mathrm{C}_{\mathrm{DGT}} / \mathrm{C}_{\text {soln }}$ declined at $\mathrm{pH} 9.5$ when measuring PPCPs using XAD-DGT and HLB-DGT.

When the solution $\mathrm{NaCl}$ concentration ranged from 0.0001 to $0.5 \mathrm{M}$, DGT measurement of all 14 compounds were not affected by the IS during both $24 \mathrm{~h}$ and 6 $\mathrm{d}$ deployments of DGT (Figures S4 and S5), with the ratio of $\mathrm{C}_{\mathrm{DGT}} / \mathrm{C}_{\text {soln }}$ between 0.9 and 1.1. There was no significant difference between the three types of DGT devices (ANOVA, $p>0.05$ ). Similar results were obtained in other studies, e.g. on OPFRs 
using HLB-DGT with IS varying between $0.0001-0.1 \mathrm{M} \mathrm{NaCl},{ }^{16}$ and when measuring EDCs using XAD-DGT and HLB-DGT when IS varied between 0.001 to $0.1 \mathrm{M}$

$\mathrm{NaCl} .{ }^{39}$ However, when IS increased to $0.5 \mathrm{M} \mathrm{NaCl}$, a significant reduction $(>10 \%)$ of $\mathrm{C}_{\mathrm{DGT}} / \mathrm{C}_{\text {soln }}$ was observed for triclosan $(R$ value $=0.74),{ }^{27}$ some OPFRs $(R$ value $=$ $0.6-0.8),{ }^{16}$ and some EDCs $(R$ value $=0.7-0.8),{ }^{39}$ indicating the influence of IS is related to the physicochemical property of the tested chemicals. In this study, the DGT method for measuring the psychiatric pharmaceuticals can be used in a high IS environment, such as seawaters. measurement for some psychiatric pharmaceuticals at higher contents of DOM in waters, during both $24 \mathrm{~h}$ and $6 \mathrm{~d}$ deployments of DGT (Figures S4 and S5). $\mathrm{C}_{\mathrm{DGT}} / \mathrm{C}_{\mathrm{soln}}$ values of some of the antidepressants (FHY, RIS, CLO, FMA, MIR, PER, and AMI) 357 declined significantly, when the DOM concentration increased to $12 \mathrm{mg} \mathrm{L}^{-1}$ (Figure 358 S4). However, there was no significant influence of DOM on DGT measurement for 359 the other compounds studied with $\mathrm{C}_{\mathrm{DGT}} / \mathrm{C}_{\text {soln }}$ values in the expected range of $0.9-1.1$. 360 A possible reason for the decline of $\mathrm{C}_{\mathrm{DGT}} / \mathrm{C}_{\text {soln }}$ value is that some psychiatric 361 pharmaceuticals can interact with humic acid and become bigger molecules, which 362 lowers their diffusion coefficients. The $\log K_{\text {ow }}$ of those compounds having low $363 \mathrm{C}_{\mathrm{DGT}} / \mathrm{C}_{\text {soln }}$ values $(<0.5)$ at high DOM concentrations were all $>3.5$ (except $\mathrm{MIR}$ ), 364 probably indicating these analytes are more likely be adsorbed by humic acid. 365 Another possible reason is that some pharmaceuticals adsorbed by humic acid cannot 366 be effectively taken up by the binding gels, because of competition between humic 
acid and binding resins in DGT for the target chemicals. For example, the $\mathrm{C}_{\mathrm{DGT}} / \mathrm{C}_{\text {soln }}$ values of FMA measured by MCX-DGT were all in the range of 0.9-1.1, when DOM concentrations were in the range of $0-20 \mathrm{mg} \mathrm{L}^{-1}$, while those of FMA by XAD-DGT and HLB-DGT were $<0.9$ when DOM was increased to $8 \mathrm{mg} \mathrm{L}^{-1}$ (for XAD-DGT) and $12 \mathrm{mg} \mathrm{L}^{-1}$ (for HLB-DGT). When the DOM concentration was $12 \mathrm{mg} \mathrm{L}^{-1}$, there were 6,5 and 5 analytes measured by XAD, HLB and MCX-DGT that were not in the range of $0.9-1.1$. Also, when DOM concentration was $20 \mathrm{mg} \mathrm{L}^{-1}$, there were 7,8 and 6 analytes measured by XAD, HLB and MCX-DGT were not in this range. Generally, MCX-DGT showed a little better performance for the tested pharmaceuticals than other two kinds of DGT, when DOM was in the range of 8-20 mg L-1.

\section{Effects of Diffusive Gel Thickness and Deployment Time. By transforming eq 1,} the adsorbed mass of a target analyte should linearly increase with the reciprocal of the thickness of the diffusive layers (diffusive gel + filter membrane), if a DGT device is deployed in a well-stirred solution with a constant concentration of the analyte and temperature. Figure S6 demonstrates that accumulated masses of the tested compounds are linearly correlated $\left(r^{2}=0.932-0.991, p<0.01\right)$ with the reciprocal of the diffusive layer thickness $(0.515-2.015 \mathrm{~mm})$. For most of the target analytes, the measured masses were very close to the theoretical line calculated from the solution concentrations using eq 1 , indicating accurate DGT measurement of these analytes. However, when the diffusive layer thickness was $0.515 \mathrm{~mm}$, the measured masses of RIS, CAF, MIR, AMI, BUP, and OXA by XAD-DGT and those of RIS, CAF, BUP, and OXA by HLB-DGT were slightly lower than the theoretical line $\left(\mathrm{C}_{\mathrm{DGT}} / \mathrm{C}_{\text {soln }}\right.$ 
389

390

391

392

393

394

395

396

397

398

399

400

401

402

403

404

405

406

407

408

409

410

values between 0.82 to 0.90 for these chemicals), while the phenomenon was not observed for MCX-DGT. This may be attributed to the slower uptake rate of XAD and HLB gels for these chemicals, inducing lower uptake masses when the diffusion flux was high due to a thinner diffusive layer.

For most of the target compounds, DGT measured masses had a linear correlation with increasing deployment time (3-168 h) and fitted well with the theoretical lines predicted from known solution concentrations using eq 1 (Figures 3 and S7). Similar responses to different deployment times were seen when measuring OPFRs ${ }^{16}$ and $\mathrm{PPCPs}^{27}$ using HLB-DGT and PFASs using XAD-DGT. ${ }^{26}$ However, some exceptions appeared in this study, for example, measured masses of CAF by XAD-DGT and HLB-DGT deviated from the theoretical lines after 1 or $2 \mathrm{~d}$ deployment, respectively (Figure 3). Similar observations were noted for RIS using XAD-DGT and FMA using HLB-DGT. For MCX-DGT, measured responses to all tested psychiatric pharmaceuticals fitted well with the theoretical lines, indicating that MCX-DGT is more suitable for long-term monitoring of psychiatric pharmaceuticals.

Field Trial Application in Xijiang River. Temperatures of the sampling site at Zhaoqing in August, September, and October were $28.5 \pm 1.5,29.0 \pm 0.5$ and $24.2 \pm$ $0.3^{\circ} \mathrm{C}$, respectively, while those at the Zhuhai sampling site were $29.4 \pm 1.1,29.5 \pm$ 0.5 , and $25.4 \pm 0.9{ }^{\circ} \mathrm{C}$, respectively. $\mathrm{pH}$ values at Zhaoqing and Zhuhai were $8.0 \pm 0.3$ and $8.1 \pm 0.1$, respectively. Electro-conductivity, which was used to evaluate the ionic strength, was 265-295 and 255-303 $\mu \mathrm{s} \mathrm{cm}^{-1}$ at Zhaoqing and Zhuhai, respectively while the electro-conductivity of $1 \mathrm{mM} \mathrm{NaCl}$ solution is $111 \mu \mathrm{s} \mathrm{cm}^{-1}$. Contents of 
411

412

413 Concentrations of humic acid were $10-12 \mathrm{mg} \mathrm{L}^{-1}$ and $9.5-11 \mathrm{mg} \mathrm{L}^{-1}$ converted

414 according to other literature based on the TOC contents. ${ }^{40}$ This is similar to previous

total organic carbon (TOC) were 20-24 and 19-22 $\mathrm{mg} \mathrm{L}^{-1}$ at Zhaoqing and Zhuhai, respectively. Humic acid only contributes a part of TOC in natural waters. reports for the Xijiang River. ${ }^{41,}{ }^{42}$ In summary, the environmental parameters in the grab samples were consistent with the conditions used for DGT characterization in the lab.

Figure 4 and Table S8 presents concentrations obtained from the grab samples and from DGT in August, September, and October. Most of the target psychiatric pharmaceuticals can be detected at the two sampling sites. The percentage of target analytes detected with DGT was consistent with the grab sampling. CAF had the highest concentration of $\sim 300 \mathrm{ng} \mathrm{L}^{-1}$. It is a compound which is also used as a food additive. Sometimes FHY, RIS, and MIR were present in the $10-100 \mathrm{ng} \mathrm{L}^{-1}$ range.

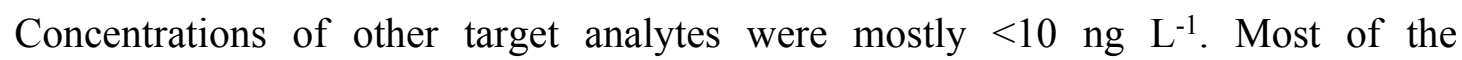
DGT-measured concentrations matched the mean values of grab samples with the $\mathrm{C}_{\mathrm{DGT}} / \mathrm{C}_{\text {grab }}$ values of 0.9 to 1.2 . Though the sampling frequency of the grab sampling was not high, the comparison between DGT measurement and grab sampling suggests DGT has a good ability to perform in field. ${ }^{16,39}$ Concentrations measured by HLBand MCX-DGT were more consistent with the mean value of grab samples. During our sampling periods, there were several heavy rainstorms and flooding caused by seasonal typhoons, which will cause variations in the concentrations of target compounds. By contrast, DGT measures time averaged concentrations conveniently 
433

and efficiently.

For most of the studied analytes, concentrations in August and September were higher than in October, maybe due to the heavy rainfall caused by the summer monsoon in August and September. There are several cities and tributaries around the two sampling points. Those cities all have several municipal sewage treatment plants and rain water outlets, and some of them have pharmaceutical factories which produce psychiatric pharmaceuticals. These are possible sources of psychiatric pharmaceuticals in Xijiang River. Psychiatric pharmaceuticals are readily adsorbed on soils because of their high $K_{\text {ow }}$. During rainy weather there are often floods in cities which may cause pollutants to flow out from drains and sewage collection facilities, bringing the contaminants from soils and tributaries to the main stream. No obvious difference was found in distribution and variation of the target chemicals between the sampling sites. Further field investigations are needed to clarify the sources of the analyte psychiatric pharmaceuticals.

Environmental Implications. The MCX binding layer performed best overall of the 3 resins tested for a new DGT suitable for psychiatric pharmaceuticals. From the comparison of the three resins, we infer that XAD and HLB-DGT can be used to measure other psychiatric pharmaceuticals and their break-down compounds, while MCX-DGT is the most suitable for these cationic compounds. Future work should address development of DGT to sample parent and breakdown products of psychiatric pharmaceuticals. This approach has recently been developed for the pesticide atrazine and its breakdown products. ${ }^{43}$ The DGT sampler is shown to be suitable for different 
455

456

457

458

459

460

461

462

463

464

465

466

467

468

469

470

471 472 and dispersal events of the chemicals, for monitoring campaigns and for

473 understanding the biogeochemical behaviour of psychiatric pharmaceuticals, such as

474 their transport mechanisms and their fate in sediments.

environmental conditions between $\mathrm{pH}$ 3-9.5, ionic strength 0.0001-0.5 M and DOM $<12 \mathrm{mg} \mathrm{L}^{-1}$. Given the uptake rates, typical environmental concentrations and typical instrument detection limits of the target analytes, the recommended deployment time of DGT devices is $>5$ days.

The field deployment showed that concentrations determined with DGT are similar to traditional spot/grab sampling, proving that DGT is a reliable method for in situ measurement of psychiatric pharmaceuticals. During the field sampling period, seasonal typhoons brought heavy rainstorms and flooding in Xijiang River and hence water fluxes and levels sharply increased, leading to variations in concentrations of psychiatric pharmaceuticals. The extreme weather events will bring risks for sampling workers who took grab samples. DGT monitoring can avoid the issue of safety problem in the extreme weather events and provide valuable data on the target chemicals during this dangerous period to understand the impact of the event on chemical concentrations. In addition, there may be cases where concentrations of psychiatric pharmaceuticals in rivers vary with time due to episodic discharges. DGT will be a better technique in these conditions as it measures the time weighted average concentrations. The newly developed method has the potential for identifying source

475 ASSOCIATED CONTENT

476 Supporting Information 

time, and storage time of binding gel on DGT performance, binding capacity and competition effect.

\section{ACKNOWLEDGMENTS}

This work was supported by Major Science and Technology Program for Water Pollution Control and Treatment (Grant No. 2017ZX07302-001) and the National Natural Science Foundation of China (No. 41771271).

\section{REFERENCES}

490 (1) Calisto, V.; Esteves, V. I. Psychiatric pharmaceuticals in the environment. Chemosphere 2009, 77 (10), 1257-1274.

(2) Whitlock, S. E.; Pereira, M. G.; Shore, R. F.; Lane, J.; Arnold, K. E. Environmentally relevant exposure to an antidepressant alters courtship behaviours in a songbird. Chemosphere 2018, 211 (1), $17-24$. antidepressants? A study of the media coverage of antidepressants in Danish online newspapers 2010-2011. Res. Social Adm. Pharm. 2018, 14 (7), 638-644. Prescriptions and Overdose Mortality in the United States, 1996-2013. Am. J. Public Health 2016, 106

500 (4), 686-688.

501 (5) Carmona, E.; Andreu, V.; Picó, Y. Occurrence of acidic pharmaceuticals and personal care products in Turia River Basin: from waste to drinking water. Sci.Total Environ. 2014, 484 (1), 53-63. rivers by liquid chromatography-electrospray tandem mass spectrometry. J. Chromatogr. A 2001, 938 (1), 175-185.

506 (7) Calisto, V.; Domingues, M. R. M.; Esteves, V. I. Photodegradation of psychiatric pharmaceuticals 507 
6097-6106.

(8) Zuccato, E.; Calamari, D.; Natangelo, M.; Fanelli, R. Presence of therapeutic drugs in the environment. Lancet 2000, 355 (9217), 1789-1790.

(9) Moldovan, Z. Occurrences of pharmaceutical and personal care products as micropollutants in rivers from Romania. Chemosphere 2006, 64 (11), 1808-1817.

(10) Yuan, S. L.; Jiang, X. M.; Xia, X. H.; Zhang, H. X.; Zheng, S. K. Detection, occurrence and fate of 22 psychiatric pharmaceuticals in psychiatric hospital and municipal wastewater treatment plants in Beijing, China. Chemosphere 2013, 90 (10), 2520-2525.

(11) Monteiro, S. C.; Boxall, A. Occurrence and Fate of Human Pharmaceuticals in the Environment. Rev. Environ. Contam. Toxicol. 2010, 202 (1), 53-154.

(12) Verlicchi, P.; Aukidy, M. A.; Galletti, A.; Petrovic, M.; Barceló, D. Hospital effluent: Investigation of the concentrations and distribution of pharmaceuticals and environmental risk assessment. Sci. Total Environ. 2012, 430 (2), 109-118.

(13) Van, d. V. K.; Keil, D.; Moens, L. N.; Hummelen, P. V.; Van, R. P.; Maras, M.; De, C. W. Effects of the antidepressant mianserin in zebrafish: molecular markers of endocrine disruption. Chemosphere 2006, 65 (10), 1836-1845.

(14) Fong, P. P.; Molnar, N. Norfluoxetine induces spawning and parturition in estuarine and freshwater bivalves. B. Environ. Contam. Tox. 2008, 81 (6), 535-538.

(15) Lajeunesse, A.; Smyth, S. A.; Barclay, K.; Sauvé, S.; Gagnon, C. Distribution of antidepressant residues in wastewater and biosolids following different treatment processes by municipal wastewater treatment plants in Canada. Water Res. 2012, 46 (17), 5600-5612.

(16) Zou, Y. T.; Fang, Z.; Li, Y.; Wang, R. M.; Zhang, H.; Jones, K. C.; Cui, X. Y.; Shi, X. Y.; Yin, D. X.; Li, C.; Liu, Z. D.; Ma, L. Q.; Luo, J. Novel Method for in Situ Monitoring of Organophosphorus Flame Retardants in Waters. Anal. Chem. 2018, 90 (16), 10016-10023.

(17) Kotwasik, A.; Zabiegała, B.; Urbanowicz, M.; Dominiak, E.; Wasik, A.; Namieśnik, J. Advances in passive sampling in environmental studies. Anal. Chim. Acta. 2007, 602 (2), 141-163.

(18) Lima, M. F.; Pacheco, W. F.; Cassella, R. J. Evaluation of a semi-permeable membrane device (SPMD) for passive sampling of solar filters from swimming pool waters and determination by HPLC-DAD. J. Chromatogr. A 2019, 1600, 23-32.

(19) Zhao, D. M. Z., P.; Ge, L.K.; Zheng, G.J.; Wang, X.H.; Liu, W.H. The legacy of organochlorinated pesticides (OCPs), polycyclic aromatic hydrocarbons (PAHs) and polychlorinated biphenyls (PCBs) in Chinese coastal seawater monitored by semi-permeable membrane devices (SPMDs). Mar. Pollut. Bull. 2018, 137, 222-230.

(20) Challis, J. K.; Stroski, K.; Luong, K.; Hanson, M. L.; Wong, C. S. Field Evaluation and In-Situ Stress-Testing of the Organic-Diffusive Gradients in Thin-Films Passive Sampler. Environ. Sci. Technol. 2018, 52 (21), 12573-12582.

(21) Davison, W.; Zhang, H. In situspeciation measurements of trace components in natural waters using thin-film gels. Nature 1994, 367 (6463), 546-548.

(22) Chen, C. E.; Zhang, H.; Jones, K. C. A novel passive water sampler for in situ sampling of antibiotics. J. Environ. Monit. 2012, 14 (6), 1523-1530.

(23) Guibal, R.; Buzier, R.; Charriau, A.; Lissalde, S.; Guibaud, G. Passive sampling of anionic pesticides using the Diffusive Gradients in Thin films technique (DGT). Anal. Chim. Acta. 2017, 966, $1-10$.

(24) Fauvelle, V.; Nhutrang, T. T.; Feret, T.; Madarassou, K.; Randon, J.; Mazzella, N. Evaluation of 
Titanium Dioxide as a Binding Phase for the Passive Sampling of Glyphosate and Aminomethyl Phosphonic Acid in an Aquatic Environment. Anal. Chem. 2015, 87 (12), 6004-6009. (25) Zheng, J. L.; Guan, D. X.; Luo, J.; Zhang, H.; Davison, W.; Cui, X. Y.; Wang, L. H.; Ma, L. Q. Activated charcoal based diffusive gradients in thin films for in situ monitoring of bisphenols in waters. Anal. Chem. 2015, 87 (1), 801-807. (26) Guan, D. X.; Li, Y. Q.; Yu, N. Y.; Yu, G. H.; Wei, S.; Zhang, H.; Davison, W.; Cui, X. Y.; Ma, L. Q.; Luo, J. In situ measurement of perfluoroalkyl substances in aquatic systems using diffusive gradients in thin-films technique. Water Res. 2018, 144 (5), 162-171.

(27) Chen, W.; Li, Y.; Chen, C. E.; Sweetman, A. J.; Zhang, H.; Jones, K. C. DGT passive sampling for quantitative in situ measurements of compounds from household and personal care products in waters. Environ. Sci. Technol. 2017, 51 (22), 13274-13281.

(28) Zabow, T., Textbook of psychiatry. Churchill Livingstone/Elsevier: 2011.

(29) Ferguson, J. M. SSRI Antidepressant Medications: Adverse Effects and Tolerability. Prim. Care Companion J. Clin. Psychiatry 2001, 3 (1), 22-27.

(30) Lee, H. S.; Chang, K. J.; Choi, S. J.; Sang, B. K.; Mi, H. L.; Ko, G. I.; Dong, H. S. Simultaneous determination of aceclofenac and diclofenac in human plasma by narrowbore HPLC using column-switching. J. Pharmaceut. Biomed. 2000, 23 (5), 775-781.

(31) Zhang, H.; Davison, W. Performance Characteristics of Diffusion Gradients in Thin Films for the in Situ Measurement of Trace Metals in Aqueous Solution. Anal. Chem. 1995, 67 (19), 3391 -3400.

(32) Guo, C.; Zhang, T.; Hou, S.; Lv, J.; Zhang, Y.; Wu, F.; Hua, Z.; Meng, W.; Zhang, H.; Xu, J. Investigation and application of a new passive sampling technique for in-situ monitoring of illicit drugs in waste waters and rivers. Environ. Sci. Technol. 2017, 51 (16), 9101-9108.

(33) Challis, J. K.; Hanson, M. L.; Wong, C. S. Development and calibration of an organic-diffusive gradients in thin films aquatic passive sampler for a diverse suite of polar organic contaminants. Anal. Chem. 2016, 88 (21), 10583-10591.

(34) Batt, A. L.; Kostich, M. S.; Lazorchak, J. M. Analysis of ecologically relevant pharmaceuticals in wastewater and surface water using selective solid-phase extraction and UPLC-MS/MS. Anal. Chem. 2008, 80 (13), 5021-5030.

(35) Yuan, S.; Jiang, X.; Xia, X.; Zhang, H.; Zheng, S. Detection, occurrence and fate of 22 psychiatric pharmaceuticals in psychiatric hospital and municipal wastewater treatment plants in Beijing, China. Chemosphere 2013, 90 (10), 2520-2525.

(36) Wu, M.; Xiang, J.; Que, C.; Chen, F.; Xu, G. Occurrence and fate of psychiatric pharmaceuticals in the urban water system of Shanghai, China. Chemosphere 2015, 138, 486-493.

(37) Hass, U.; Duennbier, U.; Massmann, G. Occurrence and distribution of psychoactive compounds and their metabolites in the urban water cycle of Berlin (Germany). Water Res. 2012, 46 (18), 6013-6022.

(38) Lajeunesse, A.; Gagnon, C.; Sauvé, S. Determination of Basic Antidepressants and Their N-Desmethyl Metabolites in Raw Sewage and Wastewater Using Solid-Phase Extraction and Liquid Chromatography-Tandem Mass Spectrometry. Anal. Chem. 2008, 80 (14), 5325-5333.

(39) Chen, W.; Pan, S.; Cheng, H.; Sweetman, A. J.; Zhang, H.; Jones, K. C. Diffusive gradients in thin-films (DGT) for in situ sampling of selected endocrine disrupting chemicals (EDCs) in waters. Water Res. 2018, 137, 211-219.

(40) Hall, E. S.; Packham, R. F. Coagulation of Organic Color With Hydrolyzing Coagulants. Journal 1965, 57 (9), 1149-1166. 
(41) Ye, T. J. H., J.; Liu, C.B.; Liu, W.; Liang, Y.M. Molecular weight distribution and removal of dissolve dorganic matters in Pearl River water. Water Technology (Chinese journal) 2010, 4 (3),

$598 \quad 12-16$.

599 (42) Liu, W. C., G.Q.; Zhang, J.S.; Lu. X.Y.; Liu, L.J.; Huang, H.X.; Yang, Y.X.; Liu, J.Q.

600 Concentration Variation and Removal of Humic Acids and Proteins for Drinking Water Sources of a City in South China. China water \& wastewater (Chinese journal) 2017, 33 (17), 41-45.

602 (43) Y.Y., C. E., Chen; W., Chen; J.W., Chen; X.Y., Cai; K.C. Jones; H., Zhang Development of a

603 Passive Sampling Technique for Measuring Pesticides in Waters and Soils. J. Agric. Food Chem. 2019, 604 67 (22), 6397-6406.

605 
606 Table 1. DGT blanks (3 types of binding gels), instrument quantitation limits (IQLs) 607 of targets detected by UPLC-MS/MS, $D_{\text {cell }}$ values, and method quantitation limits 608 (MQLs) for DGT during field application.

\begin{tabular}{|c|c|c|c|c|c|c|c|c|}
\hline \multirow{3}{*}{ Analytes } & \multicolumn{3}{|c|}{ DGT blank, ng/disc, $($ mean \pm SD $), \mathrm{n}=$} & \multirow{3}{*}{$\begin{array}{l}\text { IQL, } \\
\mu \mathrm{g} / \mathrm{L}\end{array}$} & \multirow{3}{*}{$\begin{array}{c}D_{\text {cell }} \text { at } \\
25^{\circ} \mathrm{C}, 10^{-6} \\
\mathrm{~cm}^{2} / \mathrm{s}\end{array}$} & \multicolumn{3}{|c|}{ MQL, ng /L } \\
\hline & \multirow{2}{*}{ XAD } & \multirow{2}{*}{ HLB } & \multirow{2}{*}{ MCX } & & & & DGT & \\
\hline & & & & & & XAD & HLB & MCX \\
\hline FHY & $0.05 \pm 0.02$ & $0.06 \pm 0.04$ & $0.13 \pm 0.07$ & 0.02 & 4.27 & 0.10 & 0.130 & 0.177 \\
\hline \multirow{2}{*}{ RIS } & \multirow{2}{*}{$0.02 \pm 0.03$} & \multirow{2}{*}{$0.03 \pm 0.03$} & \multirow{2}{*}{$0.02 \pm 0.02$} & \multirow{2}{*}{0.02} & \multirow{2}{*}{4.90} & \multicolumn{3}{|c|}{0.0621} \\
\hline & & & & & & 0.077 & 03 & 0.097 \\
\hline $\mathrm{CAF}$ & $0.1 \pm 0$ & $0.1 \pm 0$ & $0.08 \pm 0.02$ & 0.02 & 6.42 & 0.143 & 0.08 & 0.07 \\
\hline CLO & $0.03 \pm 0.03$ & 0 & $0.04 \pm 0.03$ & 0.04 & 3.57 & 0.123 & 0.157 & 0.147 \\
\hline FMA & $0.05 \pm 0.02$ & $0.02 \pm 0.01$ & $0.07 \pm 0.02$ & 0.02 & 4.44 & 0.093 & 0.150 & 0.193 \\
\hline MIR & $0.04 \pm 0.02$ & $0.08 \pm 0.01$ & $0.04 \pm 0.03$ & 0.02 & 5.22 & 0.10 & 0.103 & 0.09 \\
\hline PER & $0.41 \pm 0.07$ & $0.53 \pm 0.07$ & $0.83 \pm 0.12$ & 0.1 & 3.05 & 0.850 & 0.883 & 0.867 \\
\hline AMI & 0 & 0 & 0 & 0.02 & 4.76 & 0.107 & 0.110 & 0.113 \\
\hline \multirow{2}{*}{ BUP } & \multirow{2}{*}{0} & \multirow{2}{*}{0} & \multirow{2}{*}{0} & \multirow{2}{*}{0.02} & \multirow{2}{*}{5.21} & & 0.0580 & \\
\hline & & & & & & 0.110 & 97 & 0.107 \\
\hline EST & $0.02 \pm 0.01$ & $0.02 \pm 0$ & 0 & 0.02 & 5.20 & 0.097 & 0.103 & 0.10 \\
\hline DIA & 0 & 0 & 0 & 0.02 & 5.10 & 0.097 & 0.106 & 0.110 \\
\hline TEM & $0.05 \pm 0.03$ & $0.02 \pm 0.02$ & 0 & 0.02 & 5.05 & 0.10 & 0.110 & 0.113 \\
\hline ALP & 0 & 0 & 0 & 0.02 & 4.76 & 0.113 & 0.130 & 0.130 \\
\hline OXA & $0.04 \pm 0.04$ & $0.03 \pm 0.01$ & $0.05 \pm 0.02$ & 0.02 & 4.98 & 0.10 & 0.107 & 0.150 \\
\hline
\end{tabular}

$609 \mathrm{MQL}$ was calculated using the equation: $\mathrm{MQL}=\frac{\mathrm{IQL}}{\mathrm{fe} \times \mathrm{CF}}$. For DGT, $f_{\mathrm{e}}$ is the elution efficiency, $\mathrm{CF}$

610 is concentration factor and calculated using the equation: $C F=\frac{D A t}{V \Delta g}, V$ is concentrated volume of 611 elution solution $(0.5 \mathrm{~mL})$. Here it is assumed a DGT device with a $0.015 \mathrm{~mm}$ thick PC filter 612 membrane, a $0.75 \mathrm{~mm}$ thick agarose diffusive gel, and a $0.5 \mathrm{~mm}$ thick binding gel was deployed 613 for $6 \mathrm{~d}$ at $25^{\circ} \mathrm{C}$.

614 

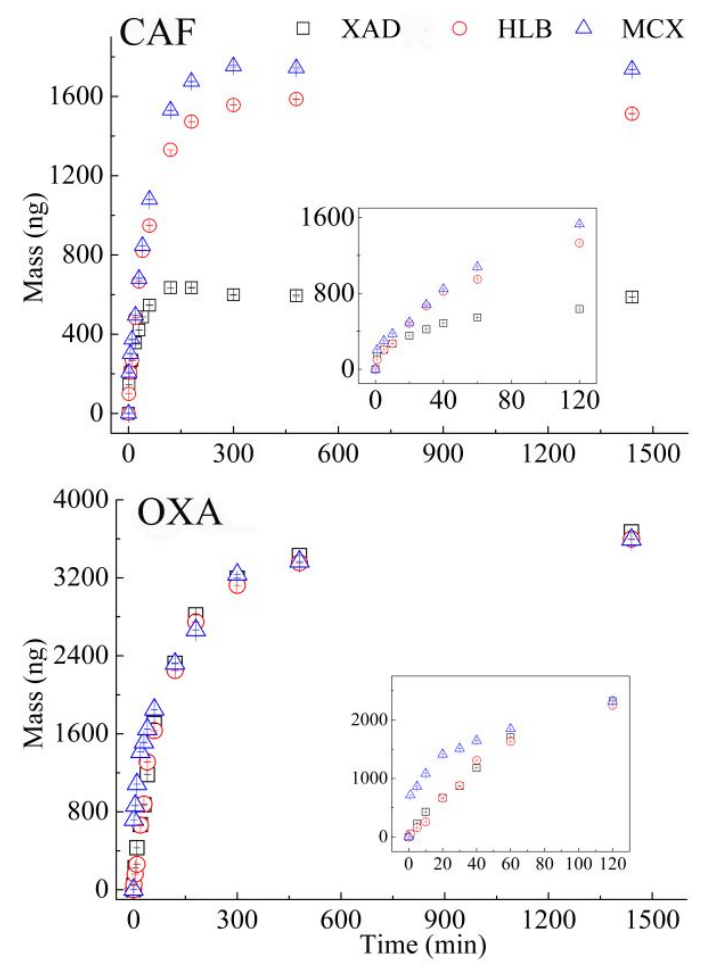

616

617 Figure 1. Masses of CAF (caffeine) and OXA (oxazepam) adsorbed by XAD, HLB, 618 and MCX binding gel discs (in $40 \mathrm{~mL}$ solutions containing $0.01 \mathrm{M} \mathrm{NaCl}$ and tested $619 \mathrm{CAF}$ and $\mathrm{OXA}$ at $100 \mu \mathrm{g} \mathrm{L}^{-1}$ ) plotted against shaking time from $0.5 \mathrm{~min}$ to $24 \mathrm{~h}$. Error 620 bars were calculated from the standard deviations of three replicates.

621 

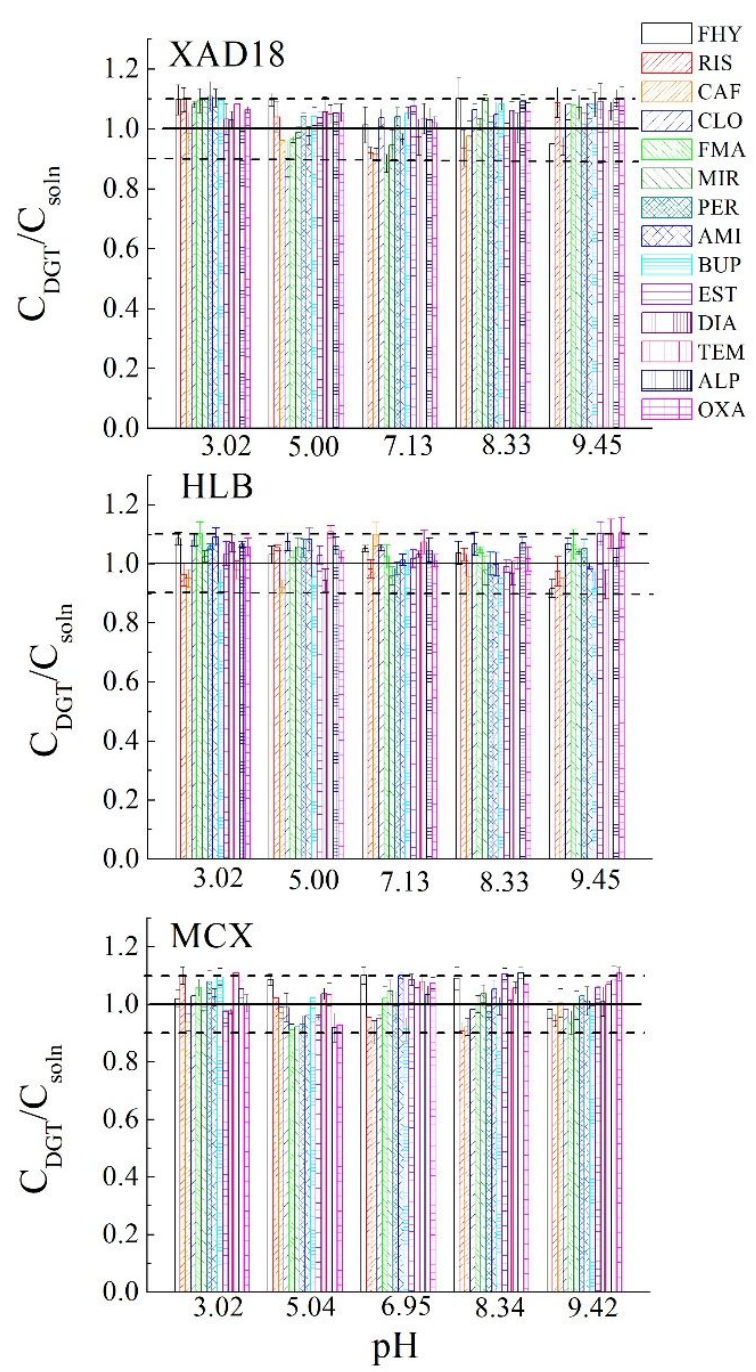

623

624 Figure 2. Effect of $\mathrm{pH}$ on the performances of XAD-DGT, HLB-DGT, and 625 MCX-DGT devices $(\mathrm{n}=3)$. The solid line and dotted lines mean target $\mathrm{C}_{\mathrm{DGT}} / \mathrm{C}_{\text {soln }}$ 626 values of $1 \pm 0.1$. Error bars are calculated from the standard deviation of three 627 replicates.

628 

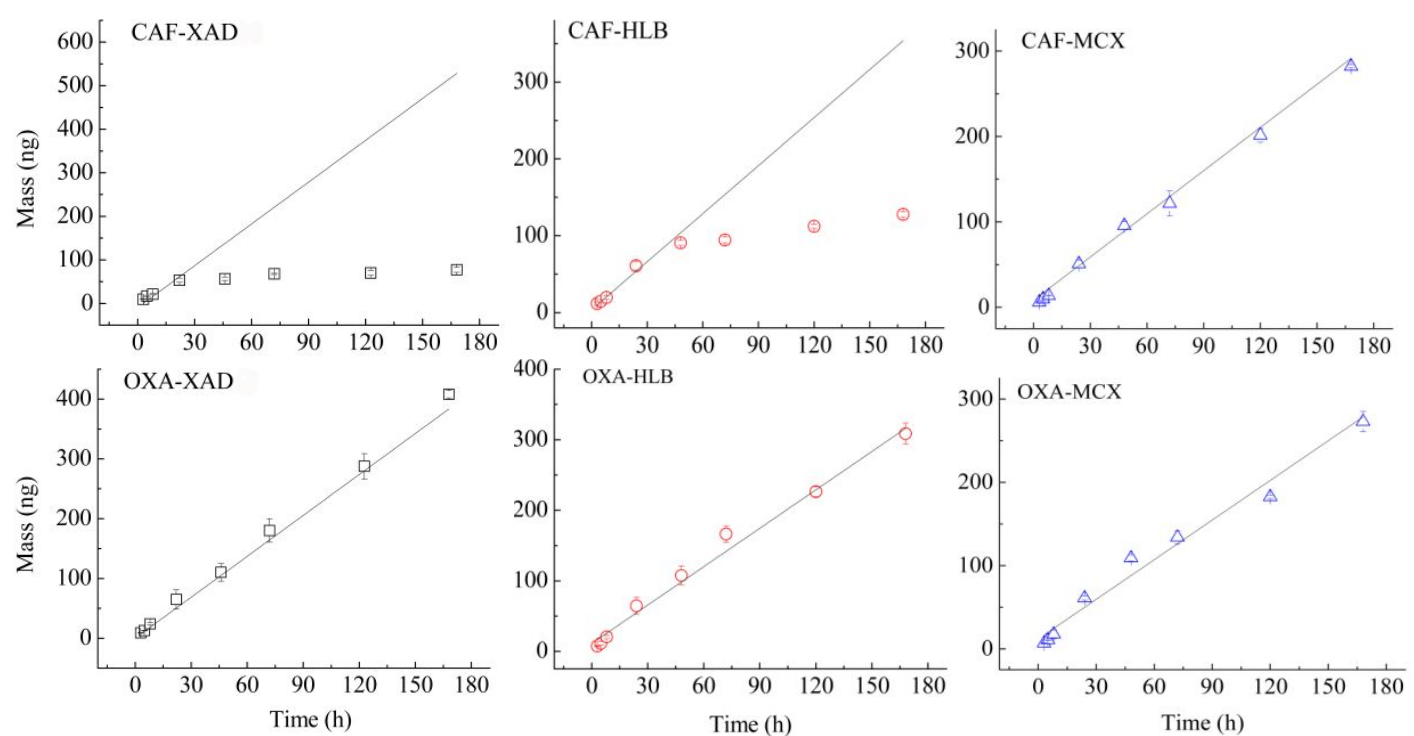

630 Figure 3. Measured masses of CAF (caffeine) and OXA (oxazepam) accumulated by

631 DGT devices containing XAD, HLB and MCX binding gels with the deployment time.

632 DGT devices deployed in $7 \mathrm{~L}$ well-stirred solutions containing $0.01 \mathrm{M} \mathrm{NaCl}$ and 633 tested psychiatric pharmaceuticals at $3 \mu \mathrm{g} \mathrm{\textrm {L } ^ { - 1 }}$ for different deployment times (3-168 634 h). $\mathrm{pH}$ was $5.65 \pm 0.2$ and the temperature was $25 \pm 0.5^{\circ} \mathrm{C}$. The solid line represents 635 the theoretical values predicted from the known solution concentrations using eq 1.

636 Error bars are calculated from three replicates. 
638

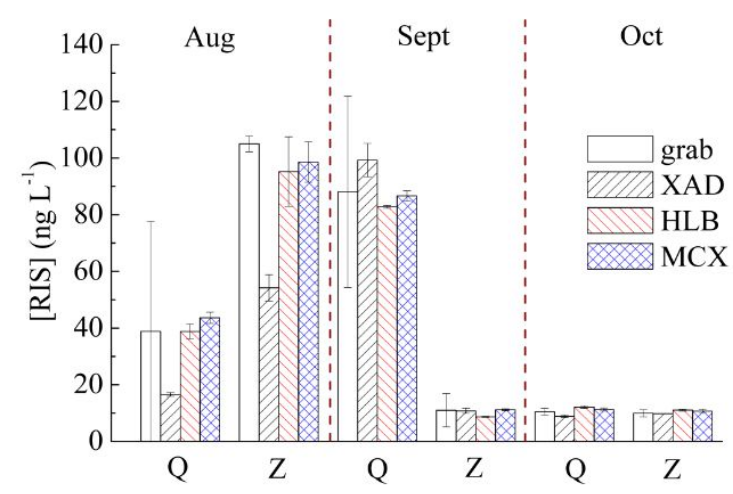

639

640 Figure 4. RIS (risperidone) concentrations measured by grab sampling and with DGT

641 at Zhaoqing and Zhuhai sampling sites in August, September, and October 2017. Q =

642 the sample site at Zhaoqing, while $\mathrm{Z}=$ the sample site at Zhuhai.

643 
644 For TOC art only

645

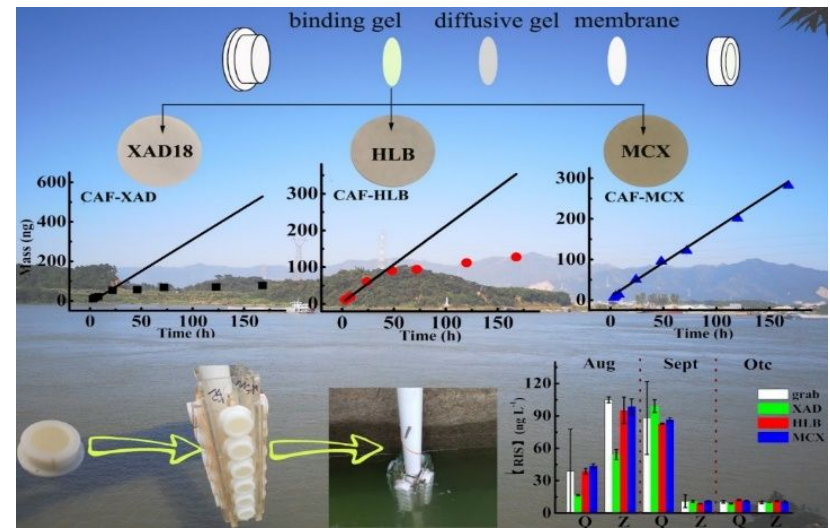

646 